\title{
Cancellation Subtest (WPPSI-IV)
}

National Cancer Institute

\section{Source}

National Cancer Institute. Cancellation Subtest (WPPSI-IV). NCI Thesaurus. Code C120520.

A subtest of the Wechsler Preschool and Primary Scale of Intelligence - Fourth Edition. As a test of processing speed the child scans two arrangements of objects (one random, one structured) and marks target objects. 